\title{
That's another story: narrative methods and ethical practice
}

Alex M Carson North-East Wales Institute of Higher Education, Plas Coch, Wrexham

\begin{abstract}
This paper examines the use of case studies in ethics education. While not dismissing their value for specific purposes, the paper shows the limits of their use. While agreeing that case studies are narratives, although rather thin stories, the paper argues that the claim that case studies could represent reality is difficult to sustain. Instead, the paper suggests a way of using stories in ethics teaching that could be more real for students, while also giving them a way of thinking about their own professional practices. The paper shows how the method can be used to develop a more critical and reflective practice for students in the health care professions. Some immediate problems with the method are discussed.
\end{abstract}

(Fournal of Medical Ethics 2001;27:198-202)

Keywords: Case study; narrative; reflexivity; identity; ethical practice

Questions regarding the use of case studies in ethics teaching have recently featured in this journal. While not dismissing their educational value, Stephen Pattison and colleagues point out some limitations on their use. ${ }^{2}$ They want to resist the idea that teachers should present case studies as reflective of real life, when they are social constructions, which are more reflective of the author's values and assumptions. They think that presenting a case study as a text or narrative rather than as a real situation would both liberate the students and encourage them to develop a more critical stance towards the text. To help develop a more critical approach to case studies, they particularly recommend the use of a formal method of literary criticism. In a reply to their concerns, Roger Higgs indicates that he does not "... think it matters much who packs the case, and how: but how it's unpacked and used, that gets us close to reality, and to good ethics". ${ }^{3}$

Higgs is less concerned about the construction of the case study, and sees the value of case studies lying in their ability to engender an imaginative and engaging discussion of the ethical issues involved. In this paper, I want to continue the conversation about the use and value of case studies in ethics teaching. While not wishing to dismiss the use of case studies, I want to show that they are more constraining than Pattison et al imagine, as well as indicating why it really does matter who packs the case. In some ways, both issues are connected through the notion of authorship. An examination of the distinction between construct and reality will bring out this connection.

\section{Case study or story?}

The titles of the papers by Pattison et al and Higgs could lead one to believe that they want to make a distinction between construct and reality. Pattison et al suspect this might be a problem for some, but they shrug this off by maintaining a distinction between texts or stories and "factual reportage" and description. Equally, the title of their paper suggests there might be a reality, which texts could be distorting or leading students away from. In a somewhat similar vein, Higgs thinks this distortion is inevitable because case studies are used in a context which is removed from "the real-life problem area" the case studies are used to examine. To all who have taken the linguistic turn, however, reality is always something we reflexively construct from within language. ${ }^{4}$ This is a critique of the idea that the truthfulness or accuracy of language could be measured against an external, objective world or reality. Language, via the linguistic turn, is seen as having a reflexive or constitutive function which rather than revealing knowledge or reality, produces or constructs that reality. To suppose that there is something outside of our language games is to suppose that case studies construct a certain reality which is at odds with a non-linguistic reality and which it is in danger of leading students away from.

Pattison and colleagues suggest that description and factual reportage are more real than case studies or texts; yet how can we know this? It seems that both Pattison et al and Higgs are working with a "something in mind", which acts as a standard or criterion, by which they judge the "realness" of narratives and case studies. I do not want to labour the point, but one can see this idea of the essential reflexivity of accounts in the work of different philosophers and more particularly in Garfinkel's Studies in Ethno-methodology. ${ }^{5}$ This work is a critique of our commonsense assumption that we are lining up our actions to an objectively real situation, when we are really subjectively producing or constructing this "real" situation. In other words, case studies, narratives, descriptions and factual reportage are all social constructions that produce their own realities. To say that there might be a difference between them, in the way that both papers suggest, is to fail to see that the "something in mind" that they operate with is simply another 
social construction, perhaps even a reality for them I am not suggesting that I subscribe to the view that reality is purely a subjective production. For all practical purposes, we operate with an intersubjective standard for reality. This is a tacit agreement among all of us that we are all dealing with the same reality and that each of our actions and speeches can be measured against this standard. While not an absolutely objective standard for reality, it allows us to carry out our normal everyday activities. Perhaps this is what both Pattison et al and Higgs are measuring case studies against, but they don't say. In real life, this intersubjective standard puts limits on what can reasonably or intelligibly be said, while still allowing us some freedom of speech and action. For instance, a bottle can be both half-full and halfempty; case studies tell us in advance whether it is half-full or half-empty. As a minimum then, we need a model of ethics education that takes account of the fact that, in real life, we have a choice about how we describe situations. I also want to go further, however, and propose another standard that can allow us to arbitrate between descriptions. If we examine case studies against what we do in real life when we describe our own actions or other peoples, we can highlight the issues involved.

\section{Social action}

Whether I am playing the guitar or writing this text, I am engaged in social action. The temptation is to say that both actions are obviously different since their outward appearances look different. If asked to describe what I am doing, I could say that I was playing the guitar or writing. If I was, to outward appearances, playing the guitar but insisted that I was really writing a text, it might seem that there was a distinction between what I was saying and what I was doing. If I then explained, however, that playing the guitar was my method for thinking through difficult issues in the text, one might accept the description. We are usually prepared to accept that our first impressions could be wrong. While it looks, on the surface, as if I am playing the guitar, we can come to see that I am really writing a text. But am I really just playing the guitar to avoid the text? How can we know which description is real? In accepting the second description of really writing a text, what proves decisive is my identity. If I went to my son's room and found him playing on his play-station instead of doing his homework, I might be angry with him. If he then explained that playing on his play-station was helping him with his homework, I might be disinclined to believe him. Faced with a choice of two descriptions of the same situation, I might conclude that he was really avoiding his homework. The point is that descriptions of what we do are never simply reports on how things really are, but are essentially influenced by who we are; any description is a self description. In real life it does matter who is making or constructing the description. All situations can be described in a number of ways which reflect not just an author's values but also, more crucially, an author's identity. What makes case studies real, for students, is how far they identify with the story, its plot, the characters and so on. Higgs shows this in his distinction between different kinds of case study; the most real being the one where the doctor clearly identifies him or herself with the patient. What makes it unreal, however, is the fact that in reality, we do have a choice about our descriptions.

\section{Choice}

While situations often present themselves to us as real, we saw in our example that there was more than one way to describe reality. In ethics education, we need students to be aware that descriptions are choices that they make themselves. I sometimes ask students to describe our classroom in one word. Some say it is bright, while others say it is dull, big, small and so on; different descriptions of the same room. I am not interested in judging which of these descriptions is the most real but want to let the students see that all descriptions involve a choice. Since there is a relative freedom of choice in our descriptions of something so "real" as a room, they see that description is less a neutral report on an objective reality and more an evaluation. While what we do is dependent on what we see, we always have a choice in what we see. In other words, we are responsible for producing the situation or context as well as our responses to it. The students' initial impression, that they were simply describing a room, is replaced with their sense that this description was more a personal choice. Case studies, however presented, constrain these real-life choices. While many situations are so typical that there is not a moment's hesitation, it remains the case that we can always describe a situation in other ways. The fact that most of the time, we are barely conscious of making this description does not mean we cannot be more conscious of doing so.

Indeed, one might argue that case studies were a more deliberate and conscious attempt to articulate a particular description, since a teacher could see the need for a particular issue being discussed. There may be a list of issues and areas, outlined in a curriculum, which students are required to cover. In these instances, the real value of case studies lies in their ability to prescribe definite issues to be discussed. Yet we also have to accept that with this prescription comes a certain amount of constraint. I personally have no problem with the notion of coercing students into discussing some clearly defined issues. If we wish to be reflective of real life, however, ethical discussions must begin, where we always do, with a choice in how we see situations. Case studies would tend to deny us this choice, since they impose a context on us. Since there is more than one way to describe a situation, students need access to more than one description of the situation. Case studies close off this possibility by presenting only one description. Students are then limited to discussing the best methods for dealing with this case or situation. I think that in real life many ethical conflicts arise over how different participants define or describe the situation rather than 
over the best methods for dealing with a prescribed situation. In prescribing a situation in advance, case studies encourage monologues rather than critical conversations. Ethics education is about the development of critical and ethical practice. Higgs gives a good example where relatives and professionals met to discuss some difficulties. This enabled each side to see something of the situation from the other's point of view and helped each to understand the other a little better. A method, similar to Higgs's example, which I have been developing, may illustrate a more critical approach to ethics education than the case study approach. The method has evolved as part of an ongoing conversation with a colleague, Gavin Fairbairn. The method is based on the students writing their own stories.

\section{Theory and practice: a conversation}

The method is based on something we all do, from time to time. While we often make an unconscious choice of descriptions, there are circumstances where we do become more conscious of this choice. As Charles Taylor points out:

".. when we see something surprising, or something which disconcerts us, or which we can't quite see, we normally react by setting ourselves to look more closely; we alter our stance, perhaps rub our eyes, concentrate, and the like".

When we are not quite sure about what we see, we sometimes act in the way Taylor describes. In validating what we think we see, we try to gain a better grasp of what we think is there. We try and get closer to the experience rather than moving away from it. We test our eyes, our position, and try to get more focused or engaged. What is preserved in this everyday practice, is the experience itself. This method allows us to think again about our initial first impressions. As I have developed it, in ethics teaching to both qualified health care practitioners and student nurses, the idea is to encourage the students to develop as more thoughtful practitioners. Like something we do, from time to time, the method begins with our initial experience of the situation; in an educational context this first impression or experience is re-created by the students in the form of a story.

The students are told, in the first session, that this class is a safe environment in which we can tell each other stories about our practices. Initially they are asked to re-collect and write about a situation in their careers, when they were faced with a dilemma or conflict. They are asked to write about this situation, in longhand, using no more than one side of A4 paper, which they hand in. This is to establish that there really is an issue that is worth pursuing rather than just a complaint or a grudge. The standard that arbitrates here is our intersubjective standard, or commonsense view, that the story is about professional practice rather than personal slights; not all stories are suitable. Over the next few weeks, each student reads out his or her story and
Story 1 (practice 1)

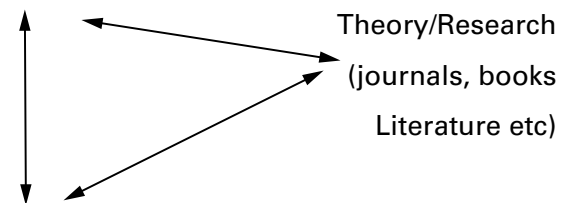

Story 2 (practice 2)

Figure 1

we spend roughly half an hour, as a group, discussing the issues raised. Sometimes the story is about a conflict with a health professional or a patient or the patient's relative. In many cases, the students support their colleague but often they do not. They are always sympathetic to each other's point of view, while making it clear where they disagree. The stories they tell are the kind of conflicts we have all faced in clinical practice.

Having written out a situation and discussed it in class, the students are then asked to write about the same situation from the perspective of the person in the story, with whom they had the conflict. As a preliminary to this task, they are reminded that they can imagine the situation from another perspective, as they already have in our classroom discussions. It is reinforced that this is not the same thing as seeing into the mind of another but is more about us having shared experiences in common. This intersubjective standard helps them in imagining the situation from another's point of view. I re-enforce that this intersubjective understanding allows us, within limits, to make assumptions about how other people might see things. ${ }^{8}$ The other general rule that they must use to guide their writing of the second story is the Socratic maxim that "No one does wrong, knowing it to be wrong". 'While some of the students are sceptical about this rule in practice, they agree to suspend judgment in the meantime.

In writing the story from another's perspective, the student's initial sense of conflict becomes somewhat subdued. When asked, however, if they think there wasn't a real conflict after all, they quickly assert that a conflict still exists. This exercise of rewriting the same situation often allows the student to become more sympathetic to the other perspective without losing their original sense of the situation. At this stage, the students have two conflicting accounts of the same situation. Stage two of the process is taken up with validating one or both of the accounts. The two accounts point to two versions of practice, which they try and validate by searching the literature. This sets up a critical dialogue between theory and practice and practice and practice as illustrated in figure 1 .

These two stories are used to guide this literature review and help to focus the students' work. As well as reflecting on their own practice, which they outline in story one, the students can also think about someone else's practice in story two. While they originally thought that the person with whom they had the conflict was wrong, they become less able 
to be critical about someone else's practice and they often back off, saying words to the effect that "I still think that they were wrong". It is usually the case that students can find literature to validate both practices/stories, although they often point out the inadequacies of the literature, particularly as a guide for practice. While this comparison of stories allows the student to see that how we see or describe situations will influence our practice, the student learns there is always a choice involved in describing situations. They also come to see that this choice is a personal choice which also reflects how they see themselves professionally. By examining both stories, they come to see that their practice is not just an interpretation but also a self interpretation.

The stories allow students to evaluate themselves as practising nurses, to see that their practice is a mix of professional duties and personal choices and interpretations. Sometimes they do not like the nurse they see, but they can come to realise that nursing practice is often a conflict between the personal and the professional. This more reflective, re-searching of their own story/practice can help the students to see or become more conscious of themselves as practitioners. The assignments they hand in are often very moving, personal accounts of situations in which they have found themselves. While we would like to think we deserve all the credit for wonderful teaching and motivating skills, perhaps the real reason can be found in the method and the students themselves.

\section{The reflexive practitioner}

The first point I want to make about stories, is that as well as being texts, they are also practices. While one is tempted to measure them against reality or to see a story as "about" something else, they are fundamentally practices. The first story the students write up is reality for them. Each story, as a reflexive practice, constructs a reality for itself. The second story is a different reality, made from the same situation. The students are confronted then with two realities, constructed from the same situation. The idea, in the remainder of the course, is for them to try and evaluate both stories; to judge which of the two stories is the better choice and the more real. While they are often unable to decide which of the two stories is better able to reflect the real situation, they do learn something about themselves and their practices. Before saying any more about the method, I should perhaps meet a possible objection to the method, namely the "mind of the other" problem.

I am conscious that the students may be less than enthusiastic to see the situation from another person's point of view, particularly if that person is someone who has deeply upset them. One must be aware, and remember, that some of the stories the students tell are ten to twenty years old. I am often amazed at how long the students have kept the anger and upset going. I think the Socratic maxim that no one acts badly, knowing the action to be bad, can help here. Even if they judge the actions to be wrong, the students can accept that the other person acted sincerely from misguided motives. This can help in balancing both accounts of the situation. In asking the nurse to write the story from another person's point of view, we might ask whether this is possible. What I am asking the nurses to do is not to be the other, but to imagine it. Since I cannot be another person, I think it would be foolish to ask for that. This fact is not a failure, however, but a necessary limit, that we all, as human beings, live with. If we could have absolute knowledge of other peoples' minds, interaction, as we know it, would be redundant. In practice, interaction is a possible solution to the "problem" of not being able to know exactly what other people are thinking. What we all live with, is a sense that we could know what others are thinking. Acting, hypocrisy, irony and other features of life rely on a certain understanding of other people as being similar enough to us for us to assume that they can know what we are talking about when we talk in this way. So knowing another person's mind cannot be a problem since it is practically impossible to do. Of course it is not impossible to think or imagine absolute or perfect knowledge; the statement that "there is no such thing as absolute knowledge" is absolute..$^{10}$ However, we don't normally think of interaction as an unhappy accommodation to this failure of absolute knowledge, so I cannot see how asking the nurses to imagine another's point of view, is any less of a failure.

Being forced to confront the situation from another's point of view often makes the students uncomfortable. If they simply wrote the second story as they originally imagined it, they would learn very little. Both stories are presented to the student, who is now asked to make a judgment about which story is the better. While one might be tempted to look to traditional ethics, whether deontological or teleological, something would be lost in the process. The use of an external criterion as a method for validating the two stories would rob the students of ownership of the stories. The main advantage of this method, compared with case studies, is that students own the experience, in the same way that teachers and professionals sometimes own the case study. An evaluation, based on utility or some other criterion, would strip out this experience by objectifying each situation. Utilitarianism can evaluate values, but only by substituting another value. In a similar way, a critical literary method simply substitutes one set of values, in the text, for another. Both approaches, utilitarianism and a critical literary method, encourage a "medical model" approach to ethics; texts are seen as objects (or bodies) that are critiqued (dissected) as a way of revealing their inner workings or values. A more reflective critical method would begin by acknowledging its own values and showing how these values influence its writing and reading of texts. Narrative methods are reflective enough to acknowledge that in reality, there is always another way to tell a story. The students have two stories and two sets of values with which to judge. What they can also come to see 
is that a major influence on their stories and practices is how they see themselves. One thing that both stories have in common is the students themselves. In evaluating both stories students can use their view of themselves as a standard. Of course, this standard can itself be validated, but that's another story.

It does matter who packs the case since we are always responsible for packing it in a certain way. Narrative methods allow the students to accept responsibility for their own cases/practices. It also allows them the opportunity to think again about their choice of contents. While they have a responsibility for their practice, narrative methods can encourage a more reflective and ethically conscious practice. Stories, written by students, can be a valuable resource for those same students as they come to see themselves and their own practice. While there may be "therapeutic" benefits for them in this process, the more educational value is in allowing practitioners to develop a more conscious and thoughtful practice. Seeing each story as an evaluation rather than a neutral description is the first step in this process. The students see that all practices/ stories are essentially constructions that depend on some things being included and others excluded, which is always, however unconsciously made, a choice. They can, in following this process, come to understand themselves better.

\section{Conclusion}

The narrative method outlined above, teaches the students to think again about their initial perceptions and practices. The assumption that underlies the use of narratives in ethics education is that everything that we do and say is constituted by our values. Case studies would tend to deny practitioners the opportunity to see that ethical arguments are often about how different groups and people see a situation. Narrative methods allow students to engage themselves in ethical discussions. As I indicated, it does not necessarily mean that students immediately change their practices. What they do get is the opportunity to bring out more of what is involved in situations that they encounter in practice. In confronting difficult issues in practice, the students can listen to the story that others involved may wish to tell. This could help in many areas of clinical practice, particularly in areas that have been traditionally seen as more about technical rationality.

In medicine itself, there has been an increased awareness of the value of a more narrative-based medicine. ${ }^{11}$ Here, the authors recommend that there should be a revival of narratives, in the teaching and practice of medicine. As they point out, modern medicine lacks a "... metric for existential qualities such as the inner hurt, despair, hope, grief, and moral pain that frequently accompany, and often indeed constitute, the illnesses from which people suffer". ${ }^{12}$

Equally, in difficult ethical situations, it is contended that doctors can learn from listening to their patient's stories rather than simply proceeding on the basis of scientific, medical knowledge. ${ }^{13}$ This could help to correct practitioners' initial impressions, which often subsume the patient's narrative within the grander narrative of the medical model. To practise with just one narrative, the medical model, is to resist the idea that there might be other ways of seeing the situation. Seeing that there is more than one story to tell could help doctors and nurses to practise in a more ethically conscious and thoughtful way. While we do tend to practise, most of the time, without thinking too deeply about our initial impressions, I think that we can, as in everyday life, re-evaluate these initial assessments. What narrative methods do is to remind us that behind every practice, there is a person, waiting to be heard.

Alex $M$ Carson, RN, PhD, is Senior Lecturer in Sociology/Ethics, Faculty of Health and Community Studies, North-East Wales Institute of Higher Education, Plas Coch, Wrexham.

\section{References}

1 Pattison S, Dickenson D, Parker M, Heller T. Do case studies mislead about the nature of reality? Fournal of Medical Ethics 1998;24:42-6; Higgs R. Do studies of the nature of cases mislead about the reality of cases? A response to Pattison et al. fournal of Medical Ethics 1999;25:47-50.

2 See reference 1: Pattison S, Dickenson D, Parker M, Heller T. 3 See reference 1: Higgs R: 50.

4 Rorty $\mathrm{R}$, ed. The linguistic turn: recent essays in philosophical method. Chicago: Chicago University Press, 1967.

5 Garfinkel H. Studies in ethnomethodology. California: Prentice Hall, 1967 .

6 Fairbairn GJ, Mead DM. Working with the stories nurses tell. Fairbairn GJ, Mead DM. Working
Nursing Standard 1992;7:37-40

Nursing Standard 1992;7:37-40
7 Taylor C. Sources of the self: the making of the modern identity. Cambridge: Cambridge University Press, 1992: 163.

8 Elliot C, Elliot B. From the patient's point of view: medical ethics and the moral imagination. Fournal of Medical Ethics 1991;17:173-8

9 For a nice discussion of the issue as a conflict with myself, see Arendt $\mathrm{H}$. The life of the mind. USA: Harcourt Brace and Company, 1977:179-93.

10 Blum A, McHugh P. Self reflection in the arts and sciences. NJ, Atlantic Highlands: Humanities Press, 1984.

11 Greenhalgh T, Hurwitz B. Why study narrative? British Medical Fournal 1999;318:48-50.

12 See reference 11: 50.

13 Hudson Jones A. Narrative in medical ethics British Medical fournal 1999;318:253-6. 